and interesting biological facts that it is too long to be of practical value. On the other hand, it is concise, factual and authoritative; essential references are given for those anxious to read more widely and sufficient formulae and diagrams are included to enable structural relationships and hormonal feed-back mechanisms to be readily grasped.

Brief introductory chapters deal with the general problems of endocrinology and the chemistry of hormones. Ten chapters follow, each dealing with a single endocrine gland, prefaced by brief descriptions of the relevant embryology and histology. Three chapters at the end describe Endocrine Factors in Growth, Maturation and Decline, the Nervous Control of the Endocrine Glands and Steroid Metabolism. There is a satisfactory index. The author is Assistant Physician to the Sydney Hospital, and the book has been printed and produced in Australia. The standard of this production is excellent and the printing clear and accurate. This is a very valuable book which deserves a wide success.

\section{THE NEUROLOGIC EXAMINATION}

By Russell N. DeJong, M.D., Professor of Neurology and Chairman of Department of Neurology, University of Michigan Medical School. Second edition. Pp. 1,078. Pitman Medical Publishing Co. Ltd., London. 1958. £7.

In the preface to this large volume, the author writes of his intention to make the work a practical guide to the neurological examination for students and practitioners of medicine. If faced with a guide of such magnitude, any medical student in this country, and most postgraduates for that matter, would undoubtedly decide never to touch neurology. The book is drawn out into a string of simplified anatomical facts and innumerable ' signs ' so beloved by some neurologists, based on the Salpétrière dogma of a past era. These signs were largely popularized in America by Wartenberg, on whose teaching DeJong heavily leans. The fundamentals of neuroanatomy and neurophysiology which are alleged to be incorporated in this book are feeble attempts to provide a basis for the localization of lesions. The scope of the neurophysiology is so limited and so simplified that even first-aid workers would find the account lacking. The specialist turning to this book for specific information will often be disappointed by a text which relentlessly misses that particular point. It is difficult to conceive how any member of the medical profession could read this book with profit and impunity. Although the standard of printing is high and the illustrations are excellent, the text could with advantage be reduced by 800 pages.

\section{DISEASES OF THE NERVOUS SYSTEM}

By Sir Francis Walshe, M.D., D.Sc., F.R.S., with chapters on 'The Neurological Complications of Liver Disease' and 'Hepatolenticular Degeneration' by J. M. WALSHE, M.R.C.P. Ninth edition. Pp. 373. E. \& S. Livingstone Ltd., Edinburgh and London. 1958. 30s.

The impression that this, the ninth edition, is much larger than previous editions is due mainly to the use of thicker paper and not expansion of the text. Two short chapters have, however, been added by Dr. John Walshe and these keep well to the tradition of this book of brevity and clarity.

This textbook of clinical neurology has already been of considerable service to innumerable medical students and as an elementary account of diseases of the nervous system it is difficult to conceive a better.

\section{RECENT ADVANCES IN CEREBRAL PALSY}

Edited by R. S. IllingworTh, M.D., F.R.C.P., D.P.H., D.C.H. First edition. Pp. 386 . J. \& A. Churchill Ltd., London. I958. 503.

The title of this book leads one to expect a present-day assessment and progress report of the clinical features, pathogenesis, disordered physiology, pathology and treatment of cerebral palsy. Little recent material is presented and very few advances. It is almost entirely from the investigative aspect of a subject that progress is made, and in this book the scientific aspects of cerebral palsy are almost completely ignored. The team of paediatricians, orthopaedic surgeons, psychologists, physiotherapists and speech therapists fail to make progress because they lack a centre-forward (or child neurologist) and several other key positions. Much amateur neurology is thrown around. What does Professor Illingworth mean when, in his opening paragraph on spasticity, he says:' A child is sometimes hypotonic in the earlier months but shows the stretch reflex and increased tendon jerks '? On the whole the American contributors, Courville, Meyers, Perlstein, and Phelps, have written interesting, readable accounts of their varying subjects. Courville's account of the structural changes in the brain in cerebral palsy is excellent and beautifully illustrated, and Meyer's contribution on neurosurgery of cerebral palsy is fascinating though highly controversial.

This subject, which lies between so many branches of medicine, needs some very clear light thrown upon it, and the sooner the scientific aspects of the problem are explored the better will be the expected results in the knowledge of how cerebral palsy is caused and from there, how it can be prevented or treated. 